\title{
Intelligent manufacture of sanitary ware structure design of vertical machine
}

\author{
Songjuan Zhu', Huachao $\mathrm{Lv}^{2 *}$, Bo Zhong ${ }^{2}$, Hui Gao ${ }^{2}$ \\ ${ }^{1}$ Hangzhou Institute of quality and technical supervision and testing, Hangzhou, Zhejiang, 310000, China \\ ${ }^{2}$ China building materials inspection and Certification Group Shaanxi Co., Ltd. Xi'an 710116, Shaanxi
}

\begin{abstract}
Firstly, the social demand of the vertical billet machine in the intelligent manufacturing of sanitary ceramics is described. Secondly, the technological process of the vertical billet machine is analyzed. The overall design scheme and implementation method of the intelligent vertical machine are proposed. Then, the key parts and functions of the vertical blank machine are analyzed and explained. Its structural characteristics, functions and characteristics are introduced, and its working principle is explained in detail. Finally, the feasibility and superiority of the erecting machine are proved.
\end{abstract}

\section{Introduction}

In recent years, with the rapid development of science and technology, the production technology of daily-use ceramics industry is also developing rapidly. Some traditional backward equipment and complex production process are being eliminated, and replaced by intelligent and automatic advanced equipment and simple process, tightly connected equipment and production line. Ceramic industry is a typical labor-intensive industry. With the development of economy and the rising of labor cost, the production efficiency of daily-use ceramic industry can be improved by improving the intelligence and automation of production process, which has become the future development trend of domestic ceramic industry $[1,2]$. Therefore, it is of great significance for China's ceramic industry to develop intelligent production line of sanitary ceramics, provide more energy-saving, environmental protection and more efficient intelligent mechanical equipment for ceramic production enterprises, reduce labor intensity, reduce production costs, improve work efficiency, improve productivity, and save energy, which is of great significance to China's ceramic industry, and also bring huge economic benefits to the society. The billet erector is an indispensable part of the intelligent production line of sanitary ceramics. The green body on the bottom mold supporting plate is modified and dried, and then enters the vertical machine. Through the rotation of the vertical machine, the green body is upright (the water tank is vertical), and the bottom of the green body is replaced with a green green green supporting plate. The plate chain mechanism of the vertical machine drives the green blank plate into the double speed line body. This process improves the efficiency of products, reduces the waste of manpower, material resources and time, and optimizes the working environment of workers.

\section{Analysis of technological process of billet erector}

\section{1 traditional erecting process}

At present, there are many kinds and styles of sanitary ceramics in China. The temperature of the grouting workshop is $36^{\circ} \mathrm{C}$ and the humidity is above $90 \%$. In order to save the cost, the mold is placed very close, the space is narrow and oppressive. After the blank is opened and the mold is erected manually. The billet is erected manually. Two workers are required to lift the blank body and the bottom mold at the same time each time, so that the blank body is erected and the bottom mold is pulled out manually. This process requires the workers to have a lot of strength, and two people have enough tacit understanding to ensure that the green body is transported, rotated and erected at the same time. Generally speaking, the traditional billet erecting technology occupies a large area, poor working environment, long working cycle, low output and high labor intensity, which requires the operators to be experienced, have certain strength and cooperate with tacit understanding. With the increase of labor cost, the requirement of working environment is higher and higher. I believe that more and more people are not willing to accept this kind of work, especially the young people nowadays. Imagine, a few years later, the ceramic factory will be able to recruit grouting workers?

\section{2 technology of vertical billet machine}

This paper takes the toilet as an example to illustrate the vertical blank. This equipment can complete the erection of the toilet with different sizes, and the process flow of the toilet with different shapes remains unchanged. The

*Corresponding author's e-mail: ctclhc@aliyun.com 
process flow of product vertical blank is shown in Figure

1.

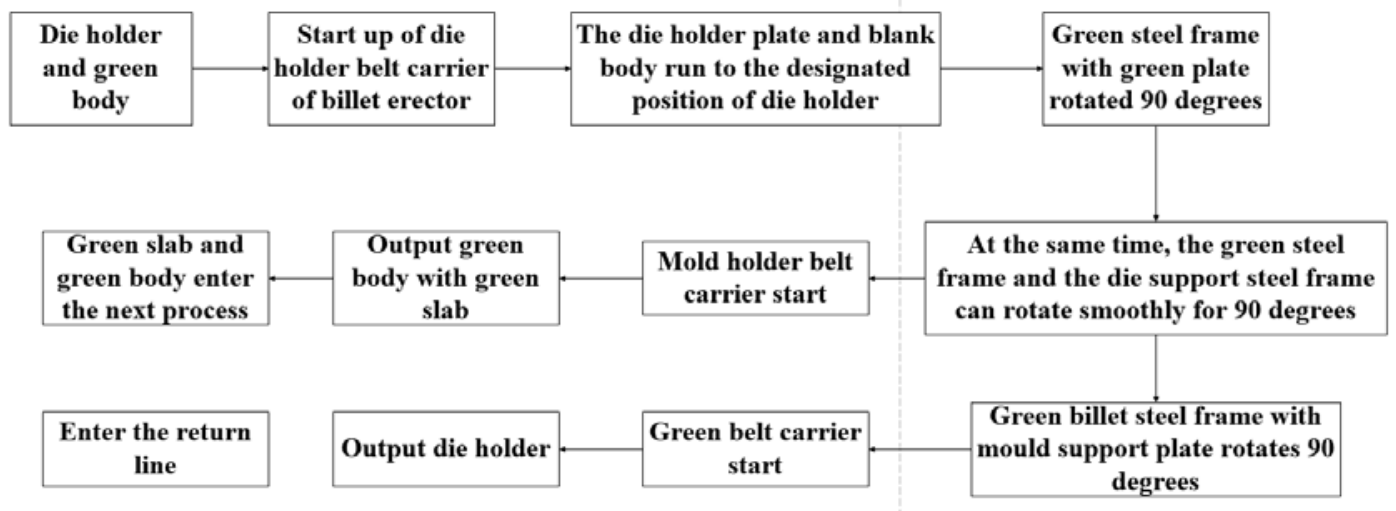

Fig 1. Vertical Slab Process Flow Chart

A return plate elevator is needed before and after the erecting machine to replace the green blank plate for the blank to be erected, and the original mold support plate after erecting the blank enters into the return plate line through the return plate elevator.

The specific process is as follows:

(1) The die support plate and the green body enter the double speed narrow line of the upper layer billet erector, return to the plate lifter before erecting, and enter the erector through the elevator belt.

(2) When the belt carrier of the billet erector starts and the belt runs, it drives the blank body and die support plate to the designated position and stops running.

(3) The green billet power frame is started, which drives the green billet steel frame and green billet belt frame to rotate $90^{\circ}$ around the circular arc rigid structure, and the green billet plate is close to the bottom of the green body, and the green body water tank is close to the mold support plate.

(4) The die holder power frame and green billet power frame move along the arc chain at the same time, driving the die holder belt carrier, green billet belt carrier and green body to rotate 90 degrees.

(5) When the green body rotates to the designated position, the die holder belt carrier returns to operation.

(6) The return plate elevator with die holder plate descends, the belt starts, and the die carrier plate is output.

(7) At the same time, green slab and green body are transported to the corresponding double speed line through green belt.

\section{Composition of billet erector}

The billet erector consists of six parts: the billet rigid frame, the green billet power system, the green billet belt carrier, the rotary system, the die carrier belt carrier and the die holder power system.

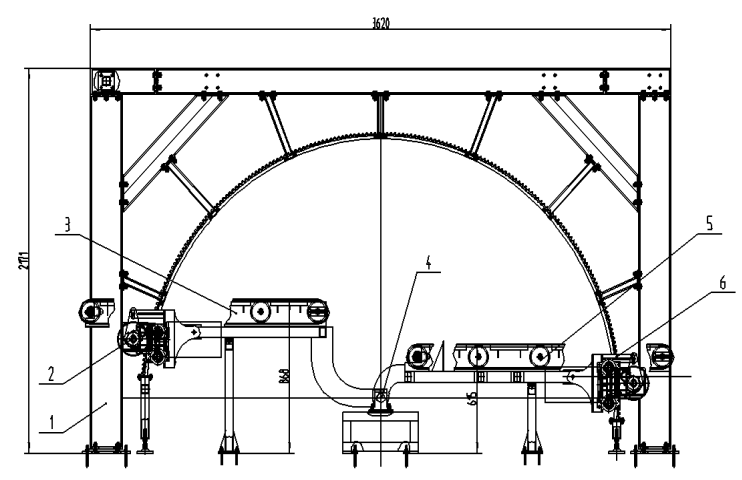

Fig 2. Vertical Billet Machine Structure Chart

1: Billet erecting machine rigid frame.2: Green billet power system.3: Green billet belt carrier.4: Rotating system.5: die carrier belt carrier.6: die holder power system

\subsection{Rigid frame of billet erector}

The rigid frame of the erector is shown in Fig. 3

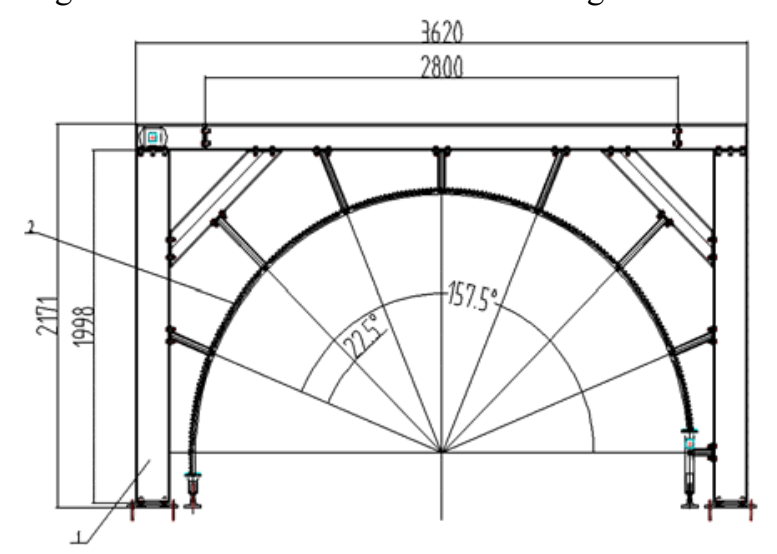

Fig 3. rigid frame of billet erector

1: Outer steel frame 2: rack gear train

The rigid frame of the billet erector consists of two parts: the outer steel frame and the rack and gear train.

The peripheral steel frame is mainly composed of different types of $\mathrm{H}$-shaped steel, which is mainly 
connected by bolts and supplemented by welding. The external frame is $3620 \mathrm{~mm}$ in length and $2171 \mathrm{~mm}$ in width. The rack gear system is composed of an arc radius of $1460 \mathrm{~mm}$. Eight groups of M8 threaded holes are opened at corresponding positions on the arc rack, and there are two threaded holes in each group, with a distance of $60 \mathrm{~mm}$. The angle difference of each two groups was 22.5 degrees. The arc rack is connected with the cablestayed beam through the threaded hole.

\section{2 composition of green billet power system}

The green billet power system is composed of motor, shaft, gear and rotating steel frame. The motor starts to drive the driving shaft and gear to rotate and move along the arcshaped rack track. At the same time, the steel frame rotates with the movement of gears. The motor is a servo motor, because the two supporting plates of the green body need to be placed vertically and horizontally. If there is a slight deviation, it will affect the automatic extraction of the blank supporting plate and the forming of the green body itself. Therefore, there is a high accuracy requirement for the rotation angle. The principle of green billet power system is the same as that of bottom mold power system. The difference is that when the two power systems are placed horizontally, the height is different. This height depends on the line going in and out of the erector, and the specific situation has been subject to the site layout. The power system of bottom mould is not explained in detail.

\section{3 green belt carrier}

The green belt carrier is composed of driving wheel, driven wheel, motor and mounting frame, limiting card and belt.

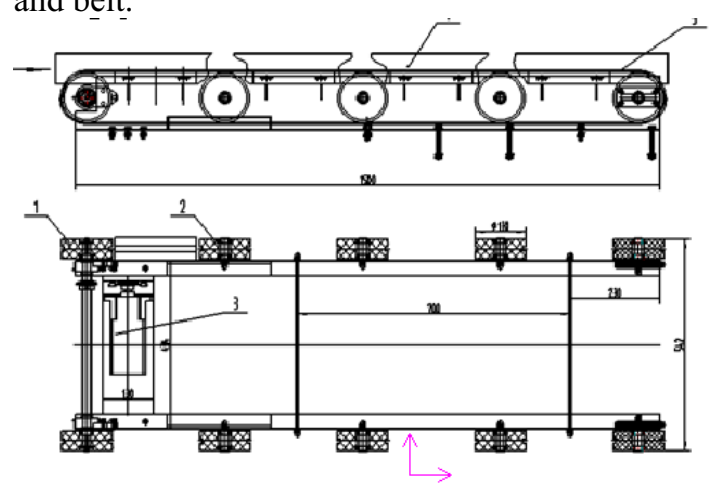

Fig 4. Green Belt Rack Chart

1: Driving wheel 2: driven wheel 3: motor and mounting bracket 4 : limit plate 5 : belt

When the supporting plate reaches the designated position, the motor starts, and the driving wheel drives the belt to run through the chain drive. The supporting plate enters the limit clamping plate and moves with the belt. After the supporting plate moves to the corresponding position, the motor stops rotating. The belt rack equipment is connected with the rigid frame of the power system. When the power system rotates, the belt carrier rotates with it. When it is rotated to the specified position, the belt carrier will perform its own corresponding action. The belt carrier acts as input and output supporting plate and green body (separate supporting plate). The principle of green belt diagram is the same as that of die holder belt diagram, so it will not be introduced in detail.

Next, I will introduce the position of the green body and different supporting plates before and after erecting.

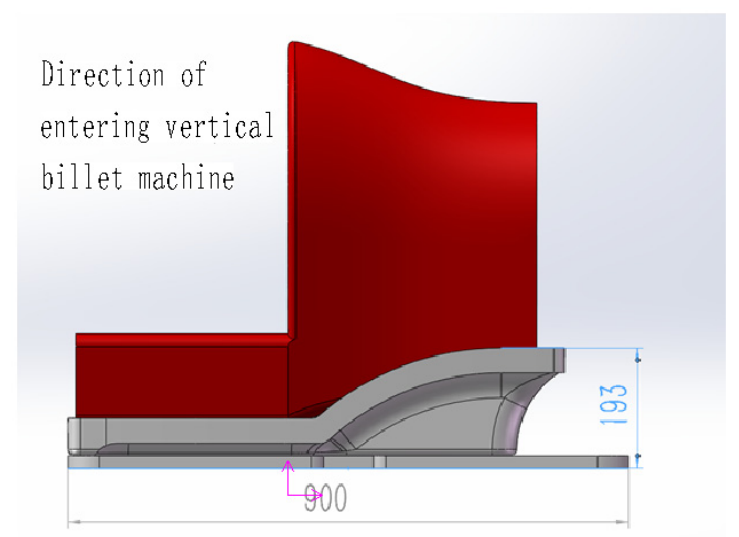

Fig 5. drawing of die holder and green body

Before erecting, the bottom of the water tank is close to the die support plate, and enters into the die holder belt bracket in the direction shown in the figure

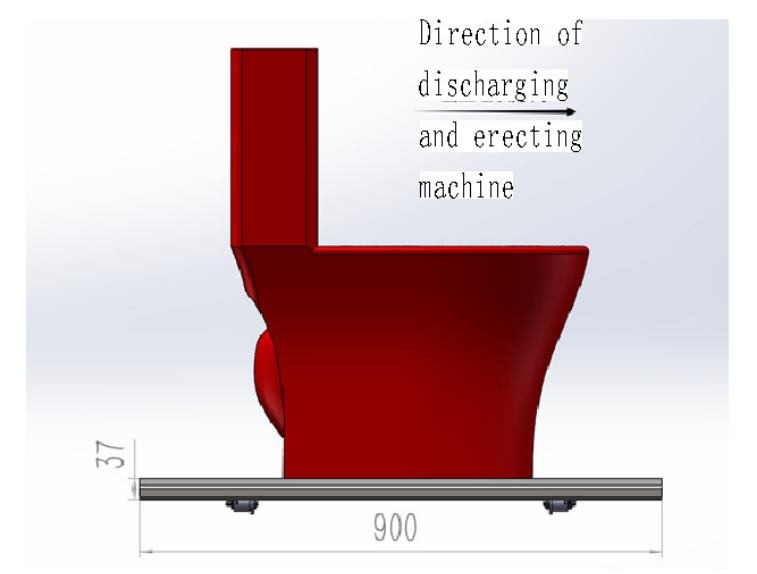

Fig 6. green slab and body diagram

After the blank is erected, the blank is replaced by the die holder plate, and the blank body is erected on the green blank plate. Send out the erector in the direction shown in the figure.

\section{Conclusion}

After debugging, the equipment can meet the production requirements of the production enterprise, replace the traditional vertical blank mode, improve the work efficiency of workers, greatly reduce the waste and loss of the blank, liberate the labor force, and achieve automatic erecting. It takes only 30 seconds to complete the erection process of a green body. The characteristics of the billet erector, such as stability, quickness and sustainability, can improve the product qualification rate and production efficiency, so as to improve the output and the income of enterprises and companies. At the same time, it can meet the production requirements of different types of 
connected toilet, which is suitable for the production and development requirements of enterprises, and has a broad development prospect. It has certain reference value and guiding significance for the design and development of other types of sanitary ceramic production line [16].

\section{Acknowledgments}

This work was supported by the study was supported by Key Research and Development Program of Shaanxi Province, China (No.2017KTPT-09)

\section{Reference}

1. $\mathrm{Xu} \mathrm{Xiwu.} \mathrm{Five} \mathrm{year} \mathrm{retrospective} \mathrm{analysis} \mathrm{on} \mathrm{the}$ output and quality of China's building and sanitary ceramics industry $[\mathrm{J}]$. China ceramic industry, 2015,22 (01): 22-26

2. Zeng Jie, Yu Haiyong, Yan Weiguo, Zhang He. Carbon footprint of building and sanitary ceramics based on life cycle theory [J]. Silicate bulletin, 2014,33 (01): 54-58+62

3. Wang Rongjie, Du Xiafang. Development status and future development trend of building and sanitary ceramics industry in China [J]. Ceramics, 2013 (06): 9-12

4. Bai Zhanying, Zhang Weixing, Liu Xiaoyun. Technical status and development trend of building and sanitary ceramics industry in China [J]. Ceramics, 2011 (12): 40-43

5. Li zewen. Development status and Prospect of domestic ceramic industry $[\mathrm{J}]$. Foshan ceramics, 2011,21 (09): 6-11

6. Nie Baomin. Development and direction of China's sanitary ceramics industry [J]. Ceramics, 2011 (04): 21-24

7. Li Jiyuan, Ma Yushu. Comprehensive experimental design of ceramic grouting molding $[\mathrm{J}]$. Science and technology innovation guide, 2013 (09): $247+249$

8. Deng Zhuming, Gou Li, ran Junguo. Rheological properties of $\mathrm{Yb}$ : YAG laser ceramic slurry prepared by grouting [J]. Silicate bulletin, 2013,32 (02): 221$224+230$

9. Li Jia. Study on the performance of plaster mold for sanitary ceramics by grouting [D]. South China University of technology, 2012

10. $\mathrm{Wu}$ Xie, Chen Zhenhua, Li Fuying. Preparation of alumina ceramic elbow by grouting method $[\mathrm{J}]$. China ceramics, 2011,47 (08): 50-53

11. Deng Shichao. Research on digital design and manufacturing technology of toilet products [D]. Hunan University, 2011 